\title{
إستراتيجية التقييم الشامل في تعليم التربية الإسلامية الموجّه إلى إنشاء الشخصية الكاملة
}

\author{
أغوس زين الفطر \\ جامعة تولونج أغونج الإسلامية الحكومية \\ شارع مايور سوجادى تيمور رقم:7 ؛ تولونج آغونغ الإسه
}

Email: guszain@yahoo.co.id

\begin{abstract}
ملخص
ينطلق هذا البحث من الافتراض أن التقييم من أصعب واجبات المدرس. الصعوبة ليست في ضعف المدرس في التقييم بل في متطلبات الحكومة التي ترجو بجاح الطلبة جميعهم ولا سيما في الامتحان الوطني. الطريقة المستخدمة في هذا البحث هي الطريقة الوصفية بالمدخل النوعي. وأساليب جمع بياناته هي الملاحظة والمقابلة ودراسة الوثائق. ونتائج البحث تدل على أن إستراتيجية التقييم الشامل في تعليم التربية الإسلامية الموجّه إلى إنشاء الشخصية الكاملة هي الآتية: (1) شفّافية نظام التقييم في بداية التدريس؛ ץ) صناعة الملاحظة اليومية؛ r) صناعة الرموز الخاصة؛ ؟) إنشاء تعليم الرفاق كالمقيّم؛ ه ) صناعة ملاحظة ”anekdot“؛؛ و \) تغيير براديجماتية المدرسين والوالدين. والعراقيل في تنفيذ التقييم الشامل في درس التربية الإسلامية هي: (1) متطلبات معيار أقل التحصيل الدراسي؛ ؟) متطلبات رئيس المدرسة والوالدين؛ ب) متطلبات المرحلة التربوية اللاحقة؛ ع) عدم الحصول على معيار تعليم التربية الإسلامية في المرحلة التربوية السابقة؛ ه) عملية التعليم لم بحر واقعية؛ ج) قلة القدوة من المدرسين؛ و قلة حصة تعليم التربية الإسلامية في المدرسة. الكلمات الرئيسية: التقييم، الشامل، التربية الإسلامية، الشخصية الكاملة
\end{abstract}

\section{ABSTRACT}

[Teacher has a very heavy duty, but of the many duties of teachers, the assessment is the most difficult aspect. This happens not because of the weakness of teachers in evaluating learning outcomes in schools, because of the demands imposed on him, namely that learners must pass in learning, especially in the National Exam. This research is a kind of field research with qualitative approach to engineering design multisitus collecting data through interviews, participant observation and document study. The results of this study indicate that the strategy adopted in order to authentic assessment in the form private PAI holistic done through: (1) the transparency of the system in the initial assessment of learning; (2) the manufacture of diary; (3) specific code generation; (4) development of peer tutoring as an appraiser; (5) record makers "Anecdotes"; and (6) changes in the paradigm of teachers and parents. While the problems facing the PAI authentic assessment, 
namely: (1) the demands of the KKM, (2) the demands of school leaders and parents, (3) the demands of further education, (4) not achieving the standard of learning PAI on previous education, (5) has not been a real learning process, (6) lack of exemplary teachers, and (7) lack of time studying PAI in school].

Keywords: Assessment, Authentic, Islamic Education, Holistic.

المقدمة

كان المدرس عنصرا رئيسيا في التعليم. له وظائف كثيرة منها مدير التعليم ومخططه ومعلمه ومقيّمه. وهو أيضا جزء العناصر التربوية الرئيسية سوى المناهج الدراسية والتسهيلات والمواد والأهداف الدراسية. وتلك العناصر لا تفيد إلا معها جودة العلاقة بين المدرس والطلبة في التعليم. المناهج الدراسية مثلا لم تكن جيدة إلا في أيدي المدرسين البحيدين في تنفيذها. ذلك هو السبب الذي ينزل المدرس منزلة رئيسية في التربية. من وظائف المدرس العديدة، التقييم هو أصعب الواجبات. الصعوبة ليست في ضعف المدرس في التقييم بل في متطلبات الحكومة التي ترجو بجاح الطلبة جميعهم ولا سيما في الامتحان الوطني. هذه المتطلبات تؤدي إلى محاولات المدرس على رفع درجات الطلبة من أصلها حتى ينجحوا في الامتحان

التقييم نوع الاختبارات. قال كرونباك إفا جمع المعلومات واستخدامها لوضع القرار حول

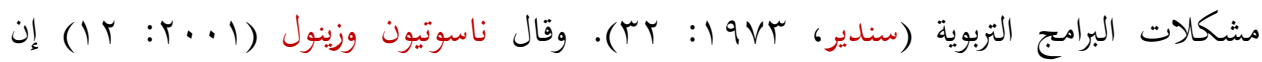
الاختبارات هي عملية أخذ القرار كمية، ومقياسها غير متعلق بسلوك الطلبة الحسنة أو السيئة وكذلك غير متعلق بمن هو ناجح وفاشل. فالمدرس في المدارس يهاول على الوصول إلى الأهداف المقررة بالطريقة التي هي أحسن. وكذلك يحاول على أن يكون مدرسا مهنيا أثناء التعليم، منها ترقية القدرة على تقييم الحاصل الدراسي. والتقييم هو تنفيذ تنوع الأساليب واستخدام نتوع الأدوات لنيل المعلومات عن الحاصل الدراسي للطلبة أو مهاراتم. والتقييم يكون على نوع التقييم النوعي والتقييم الكمّي. والتقييم في مصطلح التربية يشمل البرامج التربوية وعملية التعليم والتعلم والحاصلات الدراسية. قال سوجانا إن تقييم الحاصل الدراسي هو عملية إتاحة النتيجة لما يحصل عليه الطلبة بعد التعلم بالمعيار الخاص. وموضوع التقييم هو الحاصل الدراسي. والحاصل الدراسي هو تغيير السلوك بعد متابعة 
الدراسة. وهو يشتمل على المحال المعرفي والوجداني والحركي. ذلك لما كانت التربية في الحقيقة سعيا على إنشاء الشخصية الكاملة. لذلك، يلزم للتقييم أن يشمل تلك البحالات الثلاث.

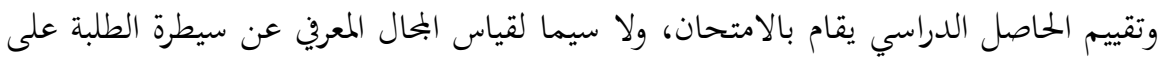

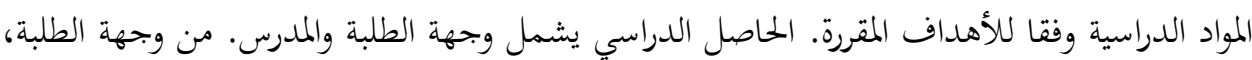

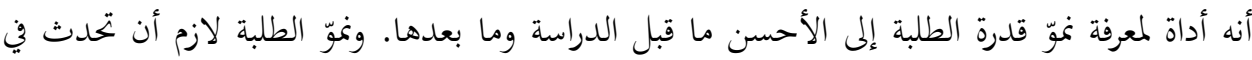

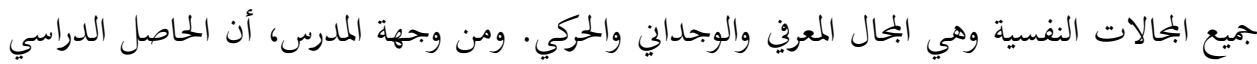

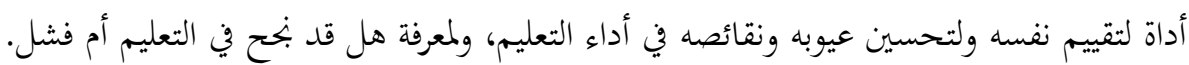

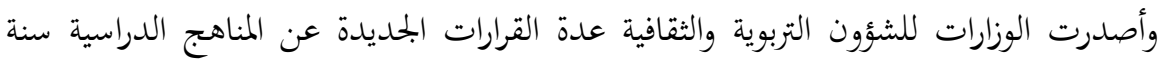

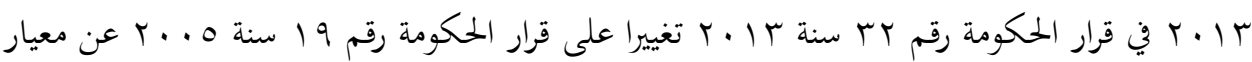

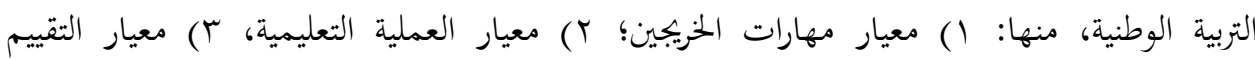

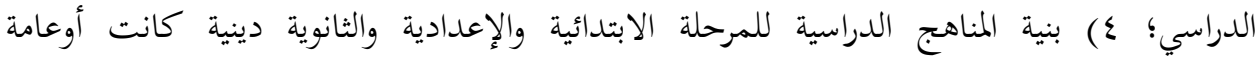

$$
\text { أومتخصصة؛ و ه) معيار الكتب الدراسية. }
$$

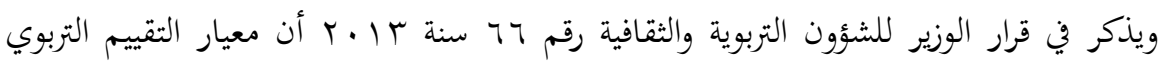

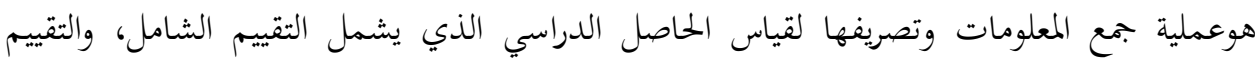

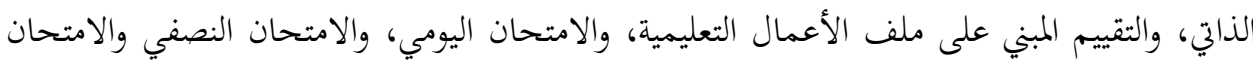

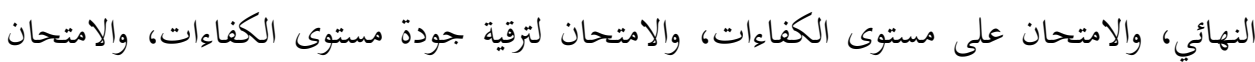

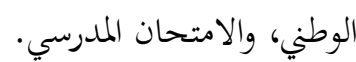

والمراد بالتقييم الشامل كما يوصف في الفصل الأول هو التقييم الذي يقيس أحوال الدراسة شاملا من الدخولات والعملية والحاصل الدراسي. لذلك، كانت كفاءات الطلبة التي يلزم ترقيتها في

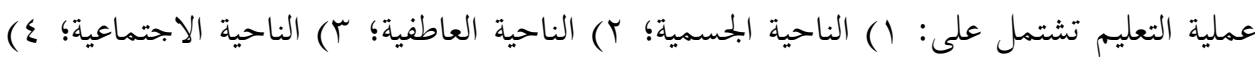
الناحية الابتكارية؛ 0) الناحية الروحية؛ وج) الناحية العلمية.

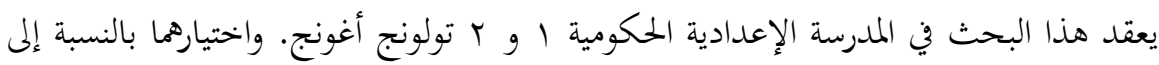

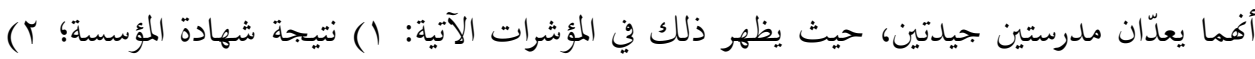

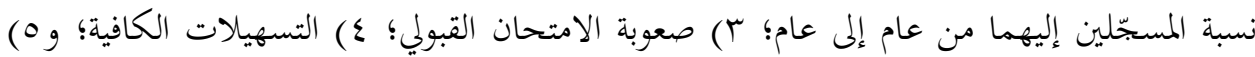

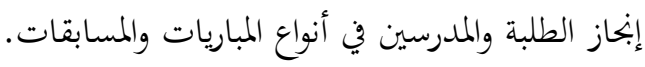


Agus Zainul Fitri

وأغراض هذا البحث تتركز إلى: ( ) معرفة مثال التقييم الشامل في مادة التربية الإسلامية في

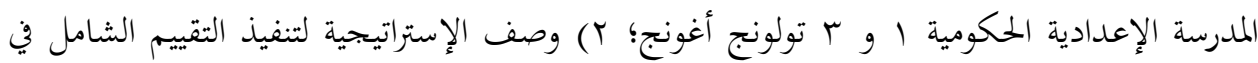
مادة التربية الإسلامية في المدرسة الإعدادية الحكومية ا و r تولونج أغونج حتى يتولد به شخصية الطلبة الكاملة؛ وب) معرفة المشكلات التي ويواجهها الدرس في تنفيذ التقييم في المدرسة الإعدادية الحكومية ا و ب تولونج أغونج.

الطريقة المستخدمة في هذا البحث هي الطريقة الوصفية، حيث يرجى بها وصف مثال التقييم

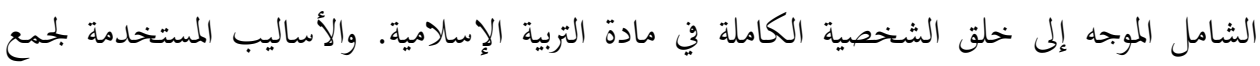
البيانات هي الملاحظة والمقابلة والدراسية المكتبية.

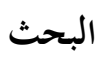

مفهوم التقييم الشامل

قال مولير (T . . r: 1) التقييم الشامل هو التقييم المباشر والقياس المباشر. وقال ويغين

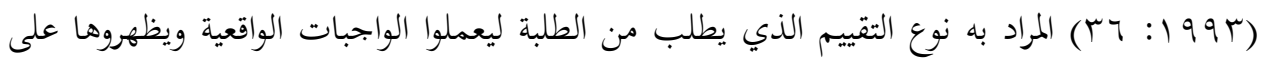
الوجه الأحسن في بجال العلم والمهارات. ورأى ستنجين (ع99 1) أنه يركز إلى المهارات الخاصة لتنفيذ معرفة الطلبة عن المواد المدروسة. والتقييم الشامل في الحقيقة، ليس لمعرفة الحاصل الدراسي فحسب بل لتقييم كفاءة المدرس نفسه في التعليم. بعبارة أخرى، يقوم المدرس بتقييم نفسه بالنظر إلى الحاصل الدراسي الذي حصل إليه الطلبة تغذية راجعة له. لذلك، يشمل التقييم الشامل جميع كفاءات الطلبة من المعرفة والموقف والمهارات الظاهرة في التفكير والعمل وحل المشكلات. ومن خصائصه "القدرة على العمل"، يعني يعمل الطلبة بشيء مبنى على المعرفة والمهارات المدروسة.

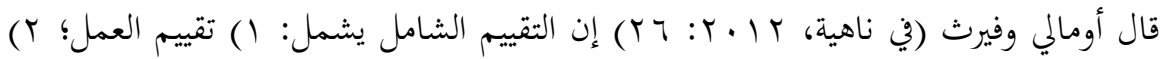
الملاحظة وعرض الأسئلة؛ r) تقديم المقالة والمباحثة؛ ؟) المعرض؛ ه) التجربة والمظاهرة؛ ج) القصة؛ V التقيم الذاتي بالطلبة؛ وم) ملف الأنشطة التعليمية والمحلة. وأداء التقييم الشامل يختلف عن أنماط التقييم التقليدي (مثل الخيارات البديلة والخطأ والصواب وإملاء الفراغ وغير ذلك)، بل إنما هو يستخدم الأنماط التي يمكن الطلبة أن يقضوا واجباتم ويظهروا مهاراتم على حل المشكلات. وأنماطه متنوعة وهي: (1) الاختبار التي تحضر الأشياء أو الحوادث الواقعية مباشرة أمام الطلبة؛ ؟) الواجبات التي توجه 
إلى عرض مهاراتم والاستقصاء البسيط والاستقصاء المتكامل؛ ؟) وتسجيل الأنشطة التعليمية مثل ملف الأنشطة التعليمية، والمقابلة وغير ذلك. وبالواجبات المتاحة، يرجى الطلبة أن يظهروا سيطرهم على المواد الدراسية والدلالة على بناحهم

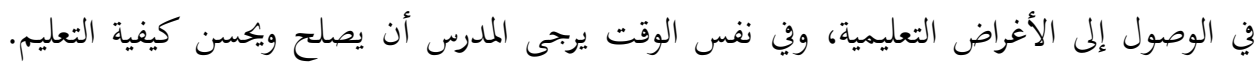
ويبدو التقييم الشامل ردّا للتقييم التقليدي الذي لا يهتم العالم الواقيعي. قال فوكاي إنه يؤدي إلى تقييم

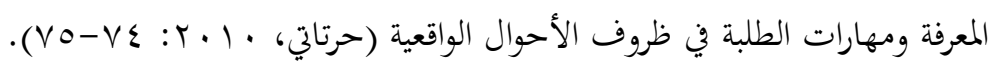

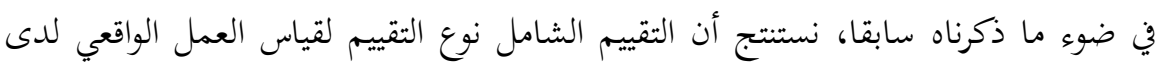
الطلبة. وقال جونسون إنه يتيح الطلبة الفرص الواسعة لعرض ما قد فهموا ودرسوا في الحجرة الدراسية.

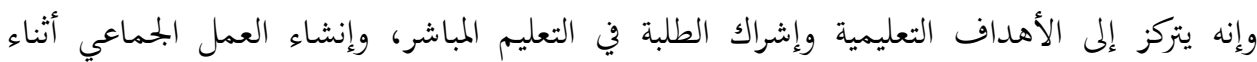

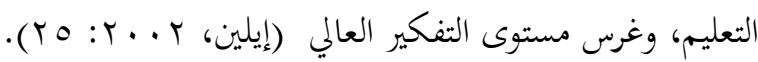

\section{مخترعات البحث}

كانت مخترعات البحث عن التقييم الشامل تتوزع إلى عدة نقاط البحث. تبدو هذه النقاط في

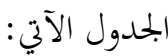

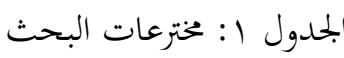

\begin{tabular}{|c|c|c|c|}
\hline المدرسة الإعدادية الحكومية r & المدرسة الإعدادية الحكومية 1 & تركيز البحث & 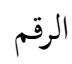 \\
\hline 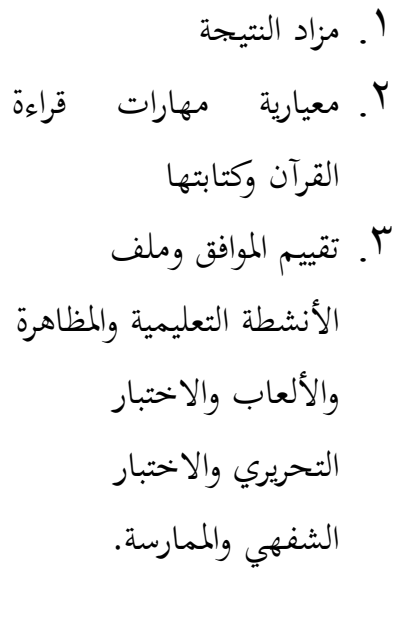 & 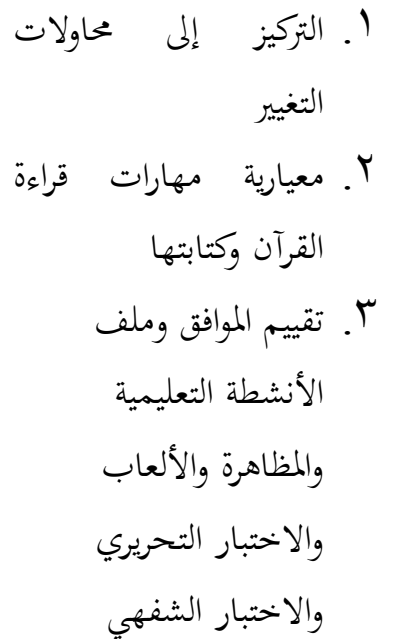 & تعليم التربية الإسلامية التقامل في & 1 \\
\hline
\end{tabular}


Agus Zainul Fitri

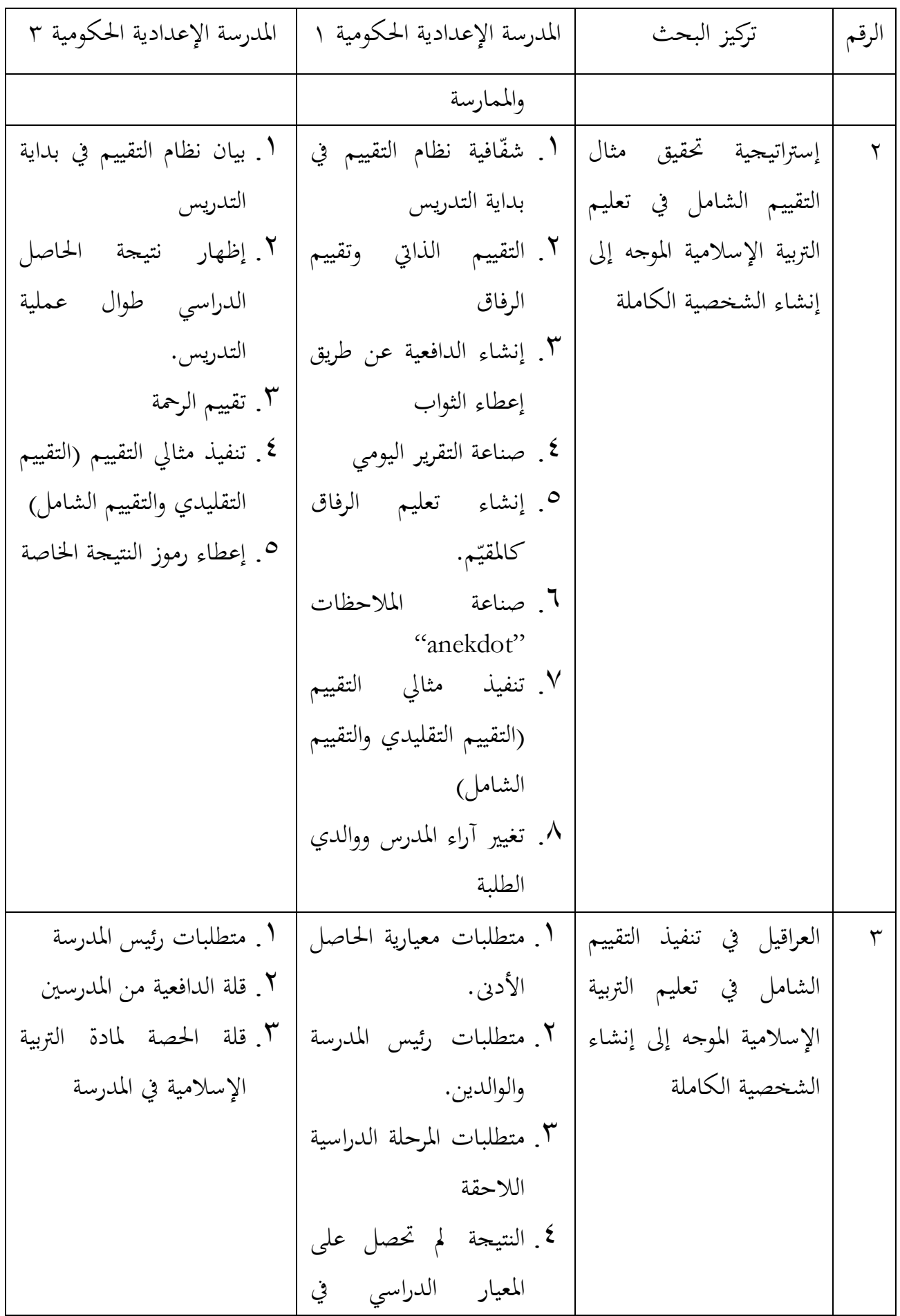




\begin{tabular}{|c|c|c|c|}
\hline المدرسة الإعدادية الحلكومية r & المدرسة الإعدادية الحلكومية ا & تركيز البحث & 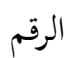 \\
\hline & 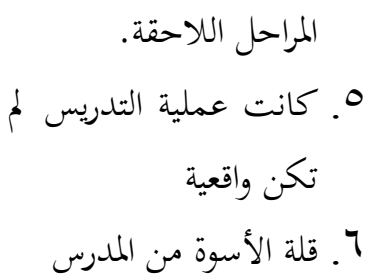 & & \\
\hline
\end{tabular}

$$
\text { أـ ـ تنفيذ التقييم الشامل في تعليم التربية الإسلامية }
$$

مزاد النتيجة إحدى المحاولات التي تقوم بها المدرسة في تعليم التربية الإسلامية لإنشاء شخصية

الطلبة الكاملة. والمدرس أساسا يسجل أداء الطلبة، والنتيجة هي تمثيل من أنشطتهم. والتقييم لا ينفصل عن عملية التدريس، لذلك كان التقييم لابد أن يمثل مشكلات الحياة الواقعية، لا المشكلات المحدودة في المدرسة.

يلزم التقييم أن يستخدم القياس والطريقة والمعيار الذي يتناسب بخصائص الخبرات التعلمية. قال

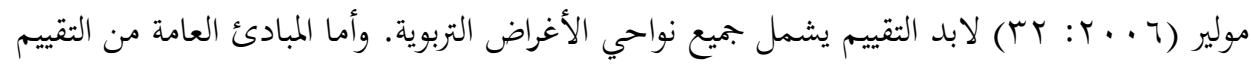

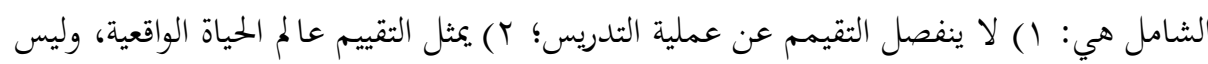
محدودا بالمشكلات حول المدرسة؛ ب) يستخدم التقييم القياس والطريقة والمعيار الذي يتناسب بخصائص الخبرات التعلمية؛ ع) التقييم يشمل جميع نواحي الأغراض التربوية، وهي الناحية المعرفية والناحية الوجدانية والناحية الحركية.

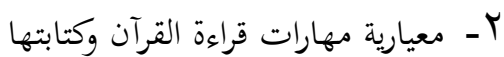

مهارات قراءة القرآن وكتابتها تعد انطلاقا في تعليم التربية الإسلامية في المدرسة. بل قال بعض المدرسين، إذا استطاع المرء قراءة القرآن وكتابتها فإنه يسهل له أن يسيطر الأخرى. مساير بذلك ما قاله سامت (ب99 19 1: ع 1) إن مؤشرات جودة التربية تظهر في مستوى حصول الطلبة على الكفاءات الكاملة التي تشمل المعرفة والانفعال والحركة يتناسب بمهاراهم. 
Agus Zainul Fitri

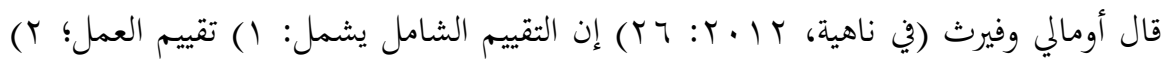
الملاحظة وعرض الأسئلة؛ ب) تقديم المقالة والمباحثة؛ ؟) المعرض؛ ه) التجربة والمظاهرة؛ ج) القصة؛ V التقييم الذاتي بالطلبة؛ وم) ملف الأنشطة التعليمية والمحلة. وأداء التقييم الشامل يختلف عن أنماط التقييم التقليدي (مثل الخيارات البديلة والخطأ والصواب وإملاء الفراغ وغير ذلك)، بل إنما هو يستخدم الأنماط التي يمكن الطلبة أن يقضوا واجباهم ويظهروا مهاراهم على حل المشكلات. وأنماطه متنوعة وهي: ( ) الاختبار التي تحضر الأشياء أو الحوادث الواقعية مباشرة أمام الطلبة؛ ب) الواجبات التي توجه إلى عرض مهاراتم والاستقصاء البسيط والاستقصاء المتكامل؛ ب) وتسجيل الأنشطة التعليمية مثل ملف الأنشطة التعليمية، والمقابلة وغير ذلك. "ا- تقييم الموقف وملف الأنشطة التعليمية والمظاهرة والألعاب والاختبار التحريري والشفهي

$$
\text { والممارسة }
$$

التقييم في المدرسة الإعدادية الحكومية ا وب تولونج أغونج يشمل تقييم الموقف وملف

الأنشطة التعليمية والمظاهرة والألعاب والاختبار التحريري والشفهي والممارسة. وتقييم الموقف مما لا ينفصل عن التقييم الشامل مهما كان نصيبه يختلف حسب اتفاق مشاورة المدرسين لمادة التربية الإسلامية.

تقييم الموقف أساسا يوجد في كل مادة دراسية، وكان موضوعه هو: 1) موقف الطلبة للمادة الدراسية؛ r) موقفهم لمدرس المادة الدراسية؛ r) موقفهم لعملية التعليم؛ ع) موقفهم لموضوع الدراسة؛ كوبه ه) الموقف الذي يتعلق بالقيم التربوية التي تتضمن في الموضوع؛ و ج) الموقف الذي يتعلق بالكفاءات الوجدانية عبر المناهج الدراسية.

العوامل التي تدافع على إنشاء الموقف في عملية التعليم ثلاثة: () الملاحظة والتقليد؛ ؟) قبول التقوية؛ ب) قبول المعلومات باللسان. وتقييم الموقف في كلتي المدرسة يستخدم قضية الموقف (يعني: موافق جدّا، وموافق، وغير موافق، وغير موافق جدّا). قال مرجونو (990 1: 9 (1) إن القضية الموقفية

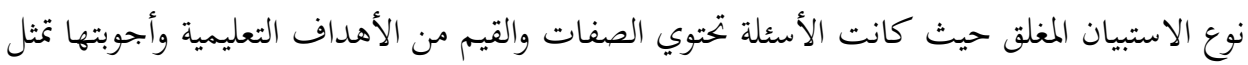
الصفات والقيم من الطلبة أنفسهم.

وملف الأنشطة التعليمية تظهر في كلتي المدرسة عن طريق إعطاء الطلبة الواجبات المنزلية والواجبات اليومية. ملف الأنشطة التعليمية هو بجموعة أعمال (واجبات) الطلبة أفرادا وجماعة في وقت 
محدود يؤدي إلى التقييم. ومن فوائدها أهما تستخدم لتقييم أداء الطلبة في قضاء واجباقم الدراسية لسنة واحدة.

$$
\text { ع- المحاولات على التغيير }
$$

تحقيق التقييم الشامل في المدرسة الإعدادية لم يتوقف بالنظرة إلى قدرة الطلبة على المواد

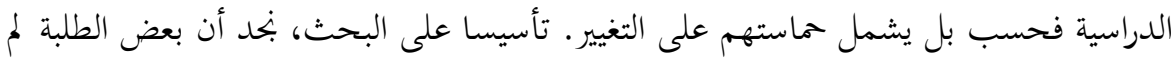

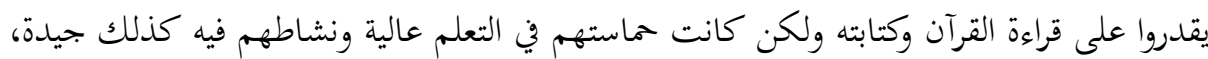

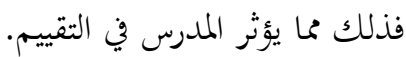

التغيير يعد انتقال حالة إلى حالة أخرى، يعني حالة قبل الدراسة وحالة بعد الدراسة (ويناردي،

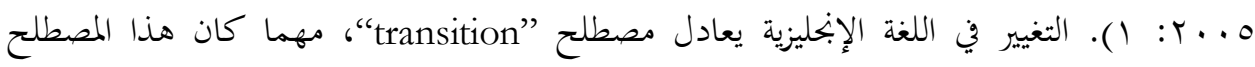

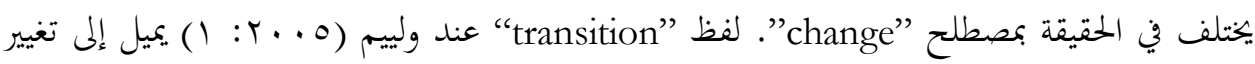
أساسي، ولفظ "change" يميل إلى تغيير عام.

التغيير هو جعل شيئ يختلف من قبل من حيث الشكل والمكان والقياس والصفة وغير ذلك.

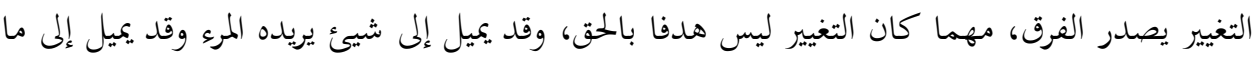

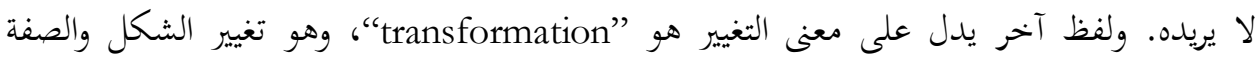

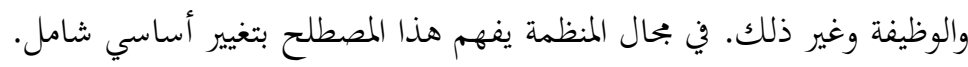

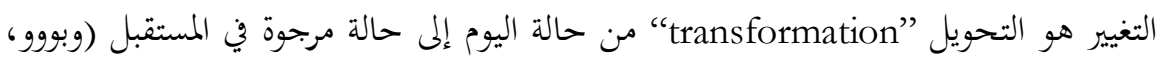
ج . . r: 1). هذا المصطلح هو المراد في هذا البحث وهو التغيير إلى حالة أحسن. وهو مِرأة الحياة.

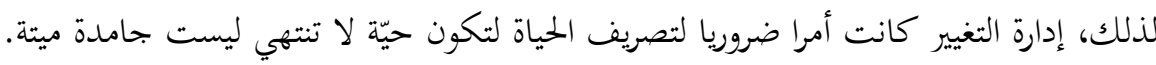

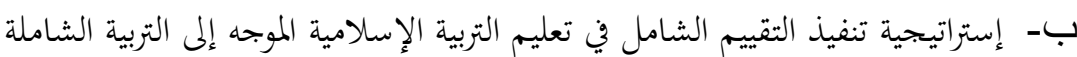
ا - شفّافية التقييم الشامل في بداية الدراسة

كان تنفيذ التقييم الشامل سيجري فعالا إذا كان المدرس يشرح نظام التقييم الشامل أمام الطلبة في بداية التدريس. هذا الرأي يتناسب بما قاله جونسون إنه يتيح الطلبة الفرصة الواسعة لإظهار

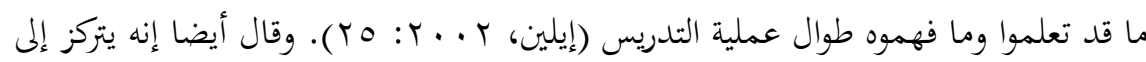

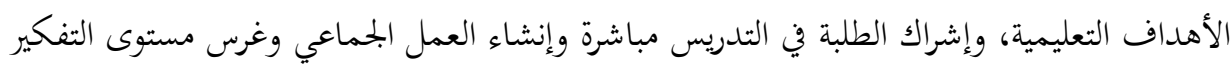
العالي. 
Agus Zainul Fitri

يتحدى الطلبة بهذا التقييم على تنفيذ المعلومات والمهارات الجديدة في الظروف الواقعية لأغراض خاصة. وهذا التقييم هو أداة لتحقيق جميع الطموح والقدرة وابتكار الطلبة. وذهب إلى ذلك باستيين وكريسنير على أنه يطلب من الطلبة على أن يستخدموا جميع الكفاءات وتزويج المعرفة والمهارة والموقف

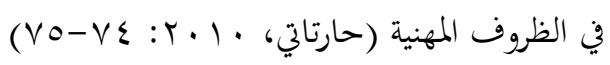

كان التقييم الشامل في تدريس التربية الإسلامية مأخوذا من عدة الأنشطة التعليمية طوال الدراسة مثل مهارة قراءة القرآن وكتابته وحفظ السور القصيرة وحفظ الأدعية البسيطة وممارسة التوضأ وممارسة الصالاة والموقف والأدب وملف الأنشطة التعليمية والتقييم الذاتي عن العبادة اليةمية ونتيجة الامتحان اليومي وقدرة الطلبة على أن يدعوا الآخرين إلى البر والامتحان لنصف الدور والامتحان النهائي وغير ذلك.

والتقييم الشامل في المدرسة يشمل ملف الأنشطة التعليمية ومهارة قراءة القرآن وكتابته وتقييم

الموقف وإرشاد الرفاق والامتحان لنصف الدور والامتحان النهائي. هذا يساير ما حقّقته المدرسة الإعدادية الحكومية تولونج أغونج كالمدرسة الدولية، حيث كانت مطلوبة للحصول على معيار النتيجة الأدنى التي قررها المدرسة نفسها، وهي • ^. هذه المتطلبات تدافع المدرسين على رفع نتيجة الطلبة إلى الأحسن أو الحصول على معيار النتيجة الأدنى على الأقل، ولو كانت تخالف التقييم الشامل.

قراءة القرآن وكتابته جزء رئيسي في التقييم الشامل ولكن المدرسين في المدرسة الإعدادية الحكومية ب تولونج أغونج يعطون النتيجة إلى جميع الطلبة ولو كان بعضهم لا يستطيعون قراءة القرآن وكتابته. ذلك لأن بعضهم يعتنقون دينا غير الإسلام. واختلاف الأديان بين الطلبة يدافع المدرسين على إتاحة نتيجة الرحمة.

بناء على البيان السابق، كانت خصائص التقييم الشامل هي: (1) التركيز إلى المادة الرئيسية أو

المهارات الخاصة؛ ب) التقييم العميق؛ r) سهولة الأداء في الفصل؛ ع) التركيز إلى جودة الحاصل الدراسي والمهارات؛ 0) تنمية السيطرة على المواد الدراسية؛ ج) تجهيز الأساليب المتنوعة التي يمكن الطلبة إظهار قدرته بعد متابعة الدراسة؛ و V) إعطاء تقدير النتيجة الذي يتناسب بحقيقة الواجب

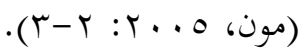

r 
الملاحظة اليومية وسيلة الإتصال بين المدرسين في المدرسة والوالدين في البيت. وهي تفيد لتسجيل أنشطة الطلبة في البيت والوالدان يوقّعان على ورقة الملاحظة. وتوقيع الوالدين على الورقة تمثيل

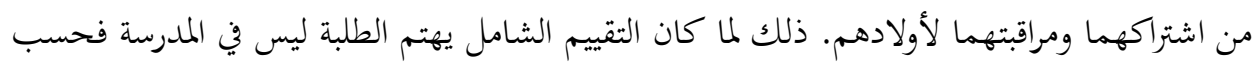
بل في الحياة الواقعية، في البيت والمختمع. ب- من اعة الرموز الخاصة في التقييم

لصون موضوعية التقييم، يلزم للمدرس ان يصنع رموزا خاصة دلالة للطلبة بالمهارات المتفوقة. مثال ذلك رمز الزيادة (+) للطلبة المتفوقين ورمز حرف (t) للناقصين أو للطلبة الذين يشعرون الصعوبة لمورية في التعليم ونيل المهارات المعينة. من فوائده يكون للمدرس تسجيلات كاملة حول أنشطة الطلبة في الفصل، مثل الحضور، وعرض السؤال والجواب ومساعدة زملائه على حل المشكلات الدراسية. وبه يعرف المدرس ما يلزمه الفعل لأفراد الطلبة من حل مشكلات التعليم. ع - - إنشاء تعليم الرفاق كالمقيّم

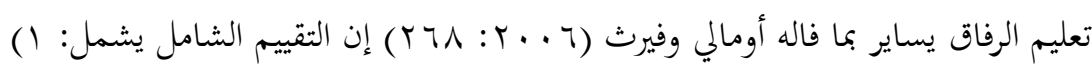

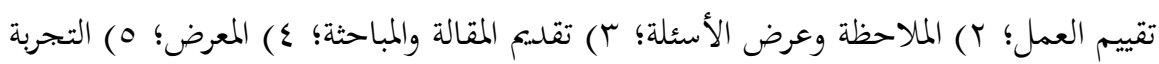
والمظاهرة؛ 7) القصة؛ V) التقييم الذاتي بالطلبة؛ و م) ملف الأنشطة التعليمية والمحلة.

تعليم الرفاق والتقييم الذاتي بين الطلبة من الأدوات التقييمية التي استخدمتها المدرسة الإعدادية الحكومية ا تولونج أغونج في التقييم الشامل. يرجى من التقييم الذاتي ترقية حماسة الطلبة على التعلم

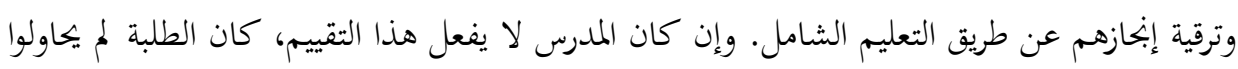
على ترقية أنفسهم في التعلم.

\section{“anekdot” ـ ـ صناعة الملاحظة}

التقييم الشامل يسمى أيضا بالتقييم المبني على نشاط الطلبة في الحجرة الدراسية. لذلك، يلزم

للمدرس ان يلاحظ ويكتب جميع أنشطة الطلبة في الفصل إما يتعلق بأدائهم ودافعية التعلم والقدرة

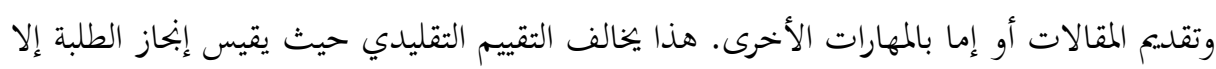


Agus Zainul Fitri

التقييم التقليدي الذي يركز إلى البمال المعرفي، يثير المدرسين ورؤيس المدرسة والوالدين في إجبار

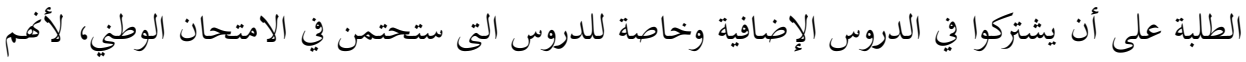

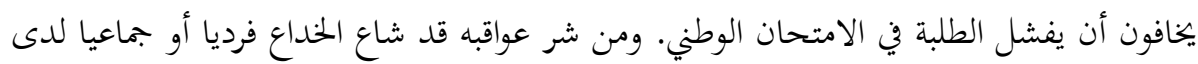
المدرسين ورئيس المدرسة من أجل بناح الطلبة فيه.

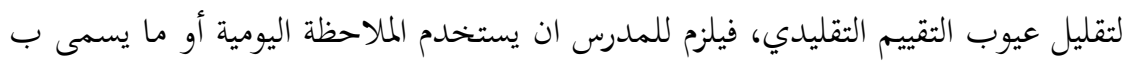

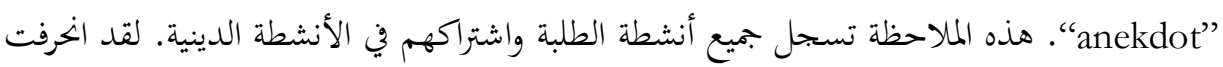

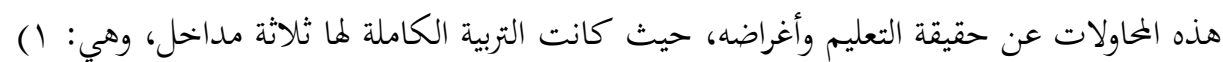
معرفة المعروف؛ ؟) الشعور وحب المعروف؛ و ب) العمل بالمعروف. معرفة المعروف ليست من العسير

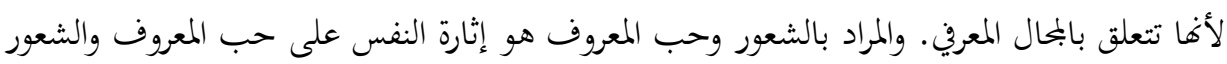

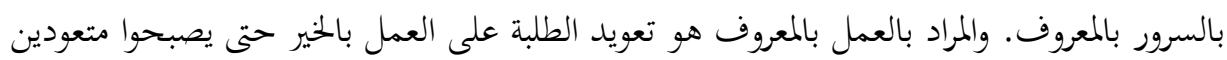

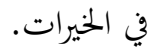

خلق الطلبة الصالحين ليس من اليسير، بل يمتاج إلى التدريب المستمر وصبر شديد. لذلك،

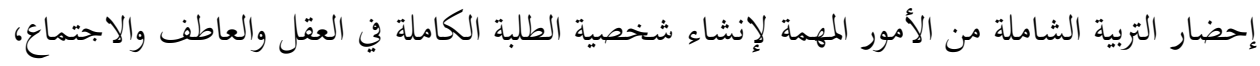

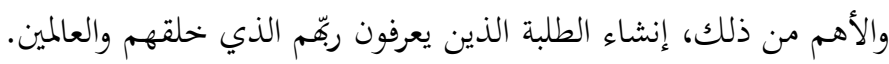

بناء على البيان السابق، فلابد للأهداف التعليمية أن تشمل القيم الفلسفية والنفسية

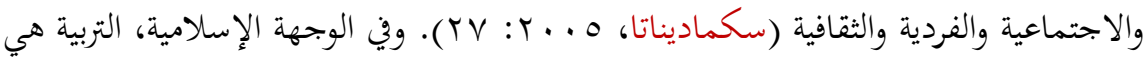

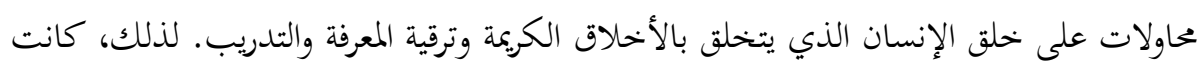
أغراض التربية هي إنشاء الإنسان الكامل.

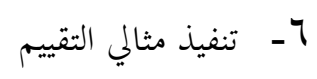

إحدى الأساليب التي يستخدمها مدرس التربية الإسلامية جمع التقييم التقليدي والتقييم الشامل. التقييم التقليدي يركز إلى تقييم البحال المعريف والتقييم الشامل يشمل جمئ الإسيع الأنشطة التعليمية. التقييم الشامل يسجل البيانات الأصلية والتقييم التقليدي يتركز إلى خصائص النتيجة الأدنى.

في الواقع، أن نظام التقييم الذي يستخدمه المدرس ورئيس المدرسة في الحقيقة لم تزل تستخدم

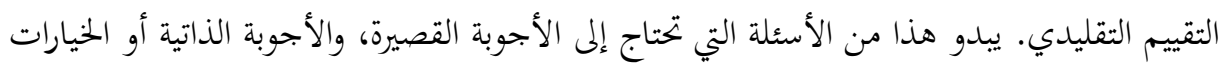


البديلة وتقييم الواجبات المعينة التي لا يعملها الطلبة في عملية التعليم. ولم يزل هذا التقييم يقيس المحال المعريف بل في المستوى المنخفض، وهو ناحية الذاكرة والفهم ولا يعطى المدرس الأسئلة لقياس البحال

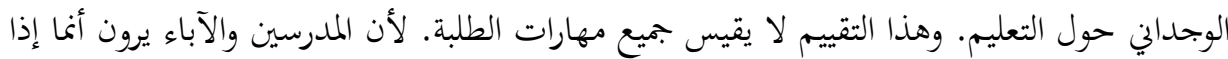
كان الطلبة غير ناجحين في الامتحان فيشعرون بأها محنة كبيرة. التقييم الشامل في الحقيقة قد قرته الوزارات للشؤون التربوية والثقافية رقم · ب سنة V . . Y عن

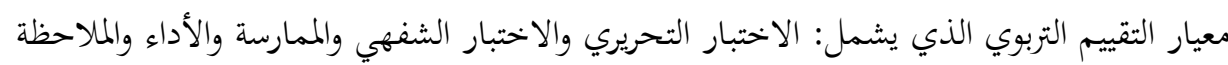
خارج التعليم وخارجه والواجبات فردية كانت وجماعية. V- ت تغيير براديجماتية المدرسين والوالدين

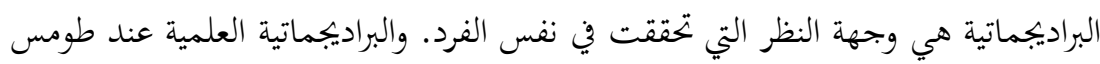

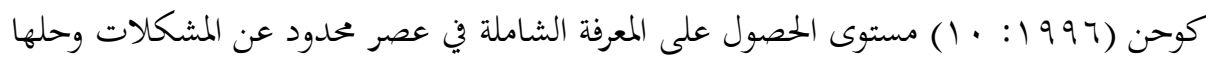

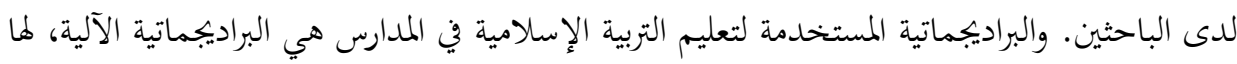

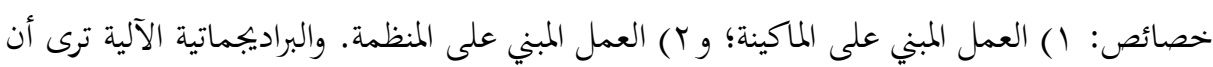

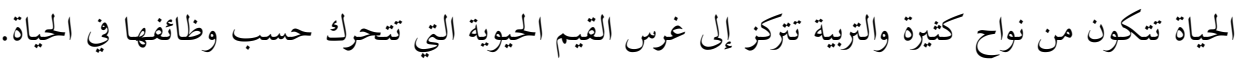
والإسلام يرى أنه يلزم على التربية تستخدم البراديجماتية الكلية (حيث يتكون من الأجزاء

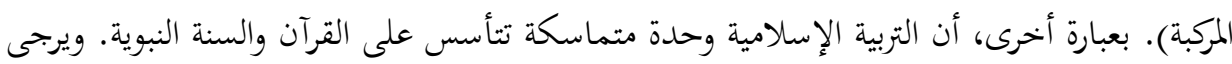

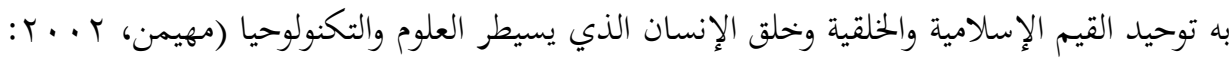

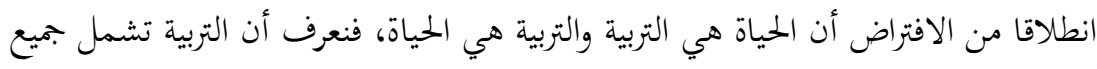

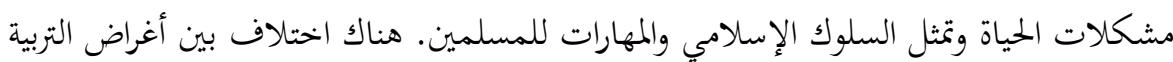

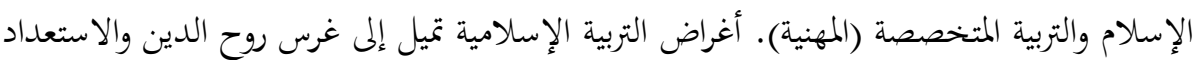

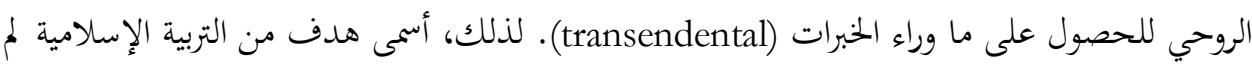

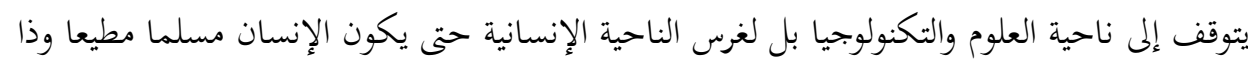

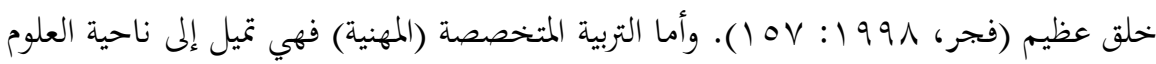


Agus Zainul Fitri

والمهارات المتخصصة حسب حوائج البمتمع والشركة. تتركز الأهداف إلى الناحية المعرفية والحركية لا إلى الناحية الروحية أو الوجدانية والشخصية.

المناهج الدراسية من عناصر التربية الرئيسية في التربية وتؤثر إلى جميع الأنشطة التربوية. لذلك،

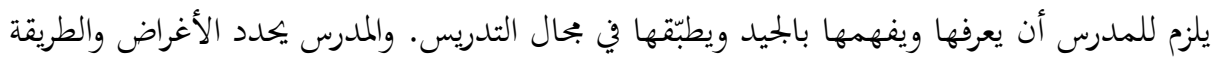

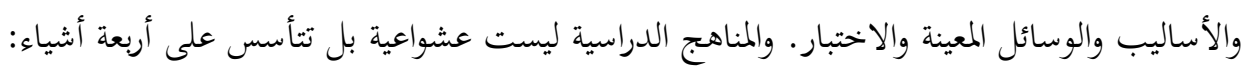

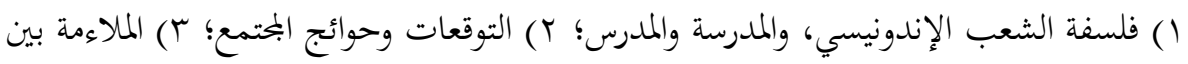

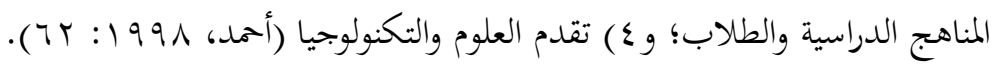
ج- العراقيل في تنفيذ التقييم الشامل في التربية الإسلامية في المدرسة

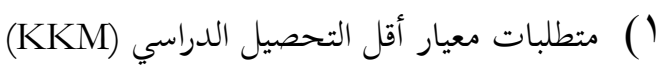

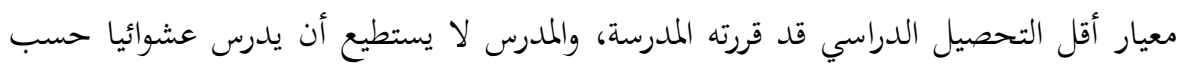

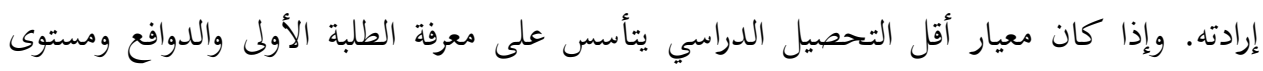

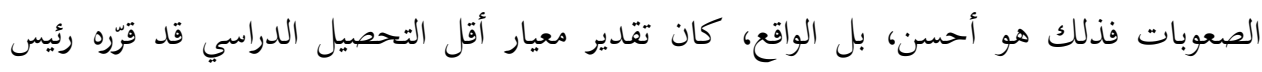

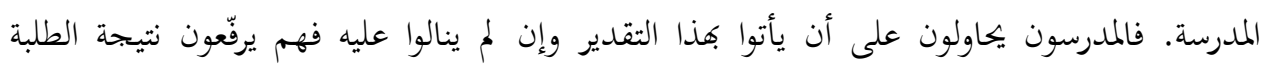
ليحصلوا عليه.

وفقا للملاحظة والمقابلة في ميدان البحث، يجد الكاتب أن المدرسين لا يرضون بالمعيار الذي

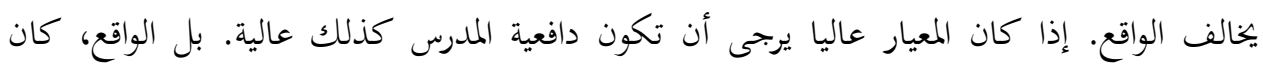

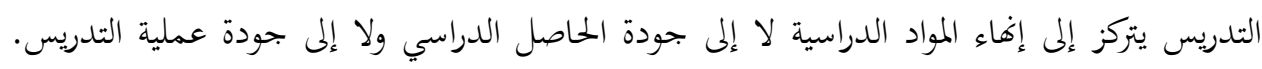

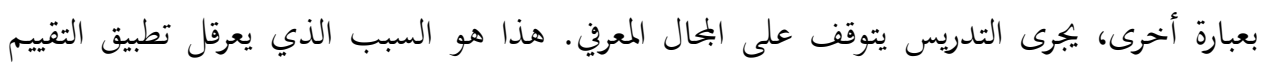
الشامل في المدرسة.

كان درس التربية الإسلامية يختلف عن غيره. الطالب الذي يعرف أركان الإيمان والإسلام قد لا

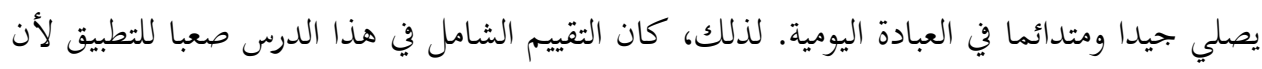

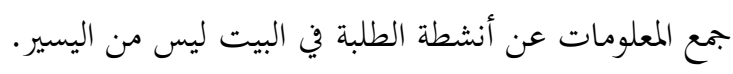
Y ( متطلبات رئيس المدرسة والوالدين 
التقييم الشامل الذي يتلاءم بمبادئه الأساسية صعب للتنفيذ في المدرسة. ذلك لما كانت المدرسة تصدر القرار المضاد العملي سرا وعلانية. وأهم الأسباب هي المحافظة على صيت التهائ المدرسة وأراء

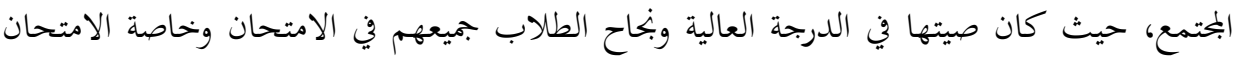
الوطني. - n

هذا الواقع يخالف أغراض التربية الإسلامية، لأفا تريد أن يكون الطلبة أفرادا صالحين لا

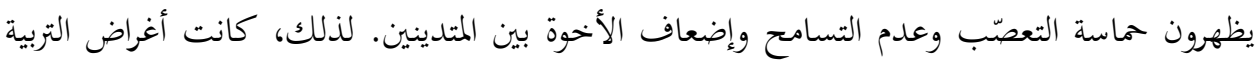

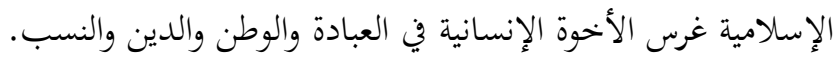

$$
\text { ب) متطلبات المراحل التربوية اللاحقة }
$$

متطلبات المراحل التربوية اللاحقة تعدّ سببا آخر تؤثر في صعوبة تنفيذ التقييم الشامل في المدرسة. المؤسسة التربية تطلب النتيجة العالية لدى الطلبة. لذلك، كان المدرسون يحاولون على أن يأتوا

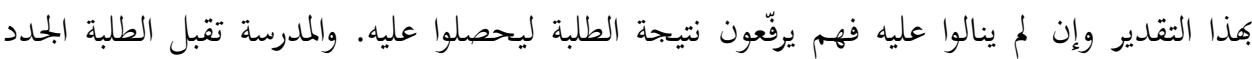
بالنسبة إلى نتيجتهم في الشهادة ولا يهتمون بالمهارات الأخرى.

نظرية تعدد المهارات (multiple intelligences) في الحقيقة تقول لنا عن عدة نقاط مهمة،

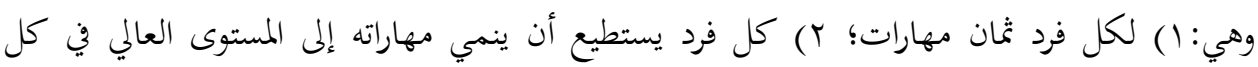

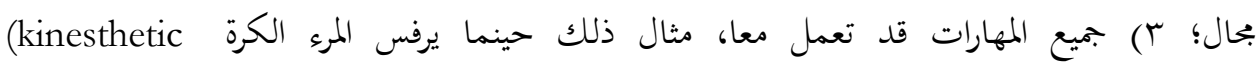

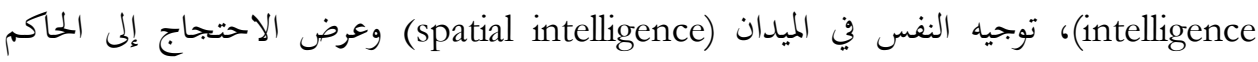

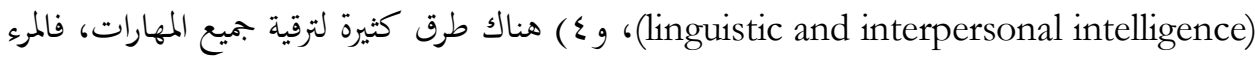

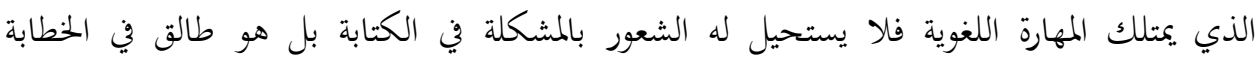
والتكلم.

نظرية تعدد المهارات تؤدي إلى إنشاء الطلبة في جميع نواحيها في الخطط التعليمية والأداء

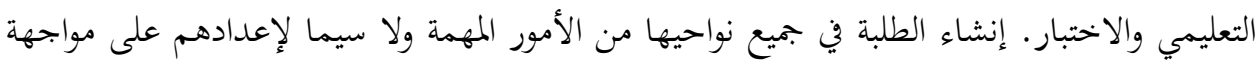
التحديات في حياتم.

§) عدم الحصول على معيار التعليم في المرحلة التربوية السابقة 
Agus Zainul Fitri

عدم الحصول على معيار التعليم في المرحلة التربوية السابقة تؤثر سلبيا في عملية التعليم في المرحلة

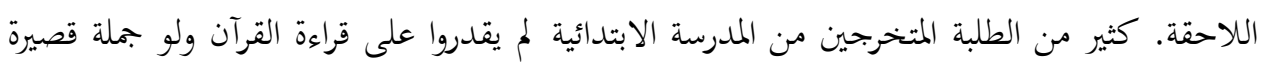

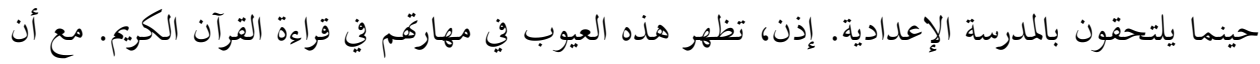
الطلبة يلزم عليهم أن يقدروا على قراءة القرآن الكريم بعد أن تخرجوا في المدرسة الابتدارئية.

معيار الكفاءات هي قياس الكفاءة الأدنى الذي يلزم على الطلبة أن يكصلوا عليه طوال الدراسة

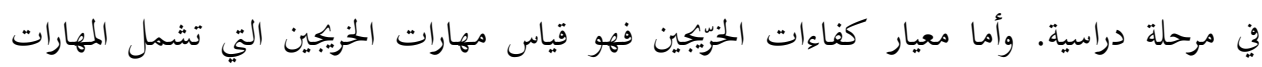

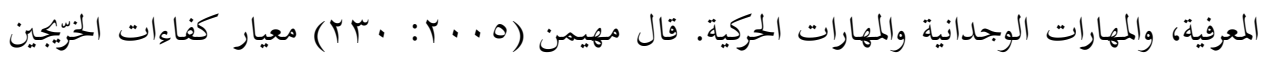

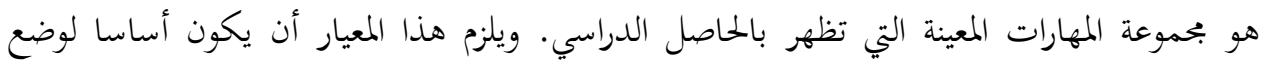

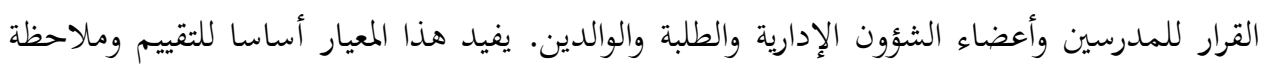
عملية الحاصل الدراسي وتقدم الطلبة.

$$
\text { 0) عملية التدريس غير الواقعية }
$$

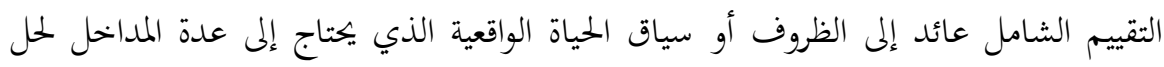

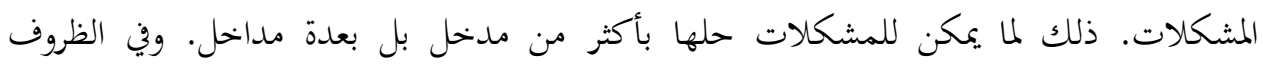

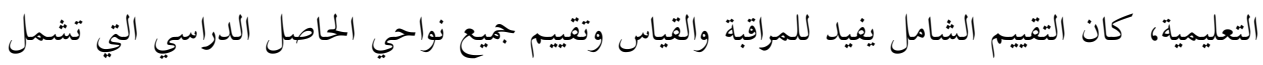

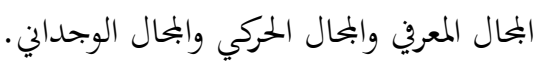

قال حارت (ع 99 () إن التقييم الشامل يدعو الطلبة للاشتراك في الواجبات الواقعية المفيدة.

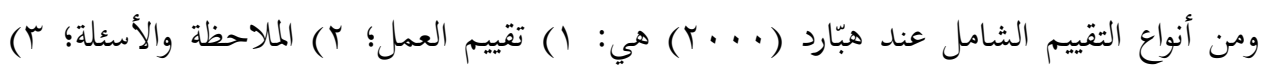

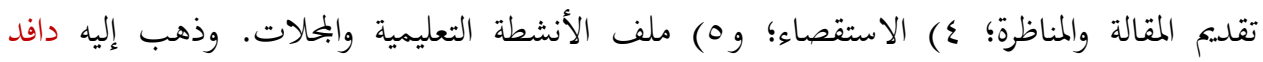

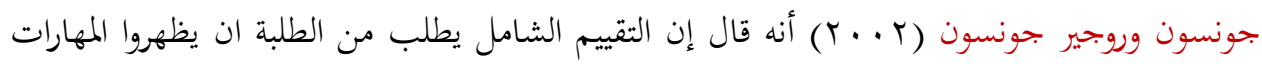
في الحياة الواقعية.

$$
\text { ד) ( قلة الأسوة من المدرسين }
$$

توجيه التقييم الشامل إلى خلق الثقافة الخلقية في العالم التربوي يتحقق بالمدنل التعويدي

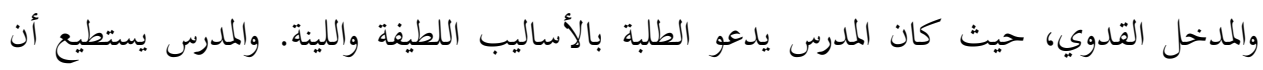

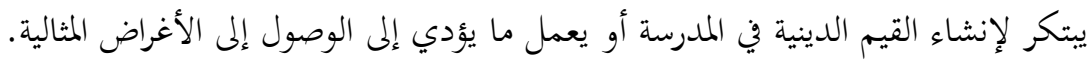




\section{هناك أربعة مداخل لتكوين الأخلاق الكريمة، وهي:}

أولا: المدخل التعليمي البنيوي (instruktif-struktural)، وهو إستراتيجية تكوين شخصية الطلبة في المدرسة تطبيقا لقرار رئيس المدرسة الذي يهتم بصدر تنوع الأنشطة الدينية وبتهيز التسهيلات

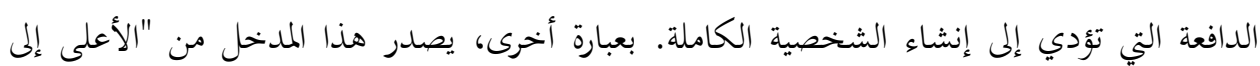
الأدنى" أي الأنشطة الدينية على قرار رئيس المدرسة.

ثانيا: المدخل الرسمي الإضافي (formal-kurikuler)، وهو إستراتيجية تكوين شخصية الطلبة في المدرسة عن طريق تكامل الشخصية المرجوة بعملية التعليم والتعلم وترقيتها في جميع المواد الدراسية.

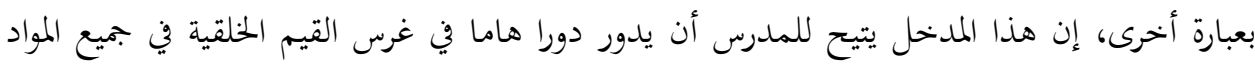
الدراسية.

ثالثا: المدخل الميكانيكي المتفرع (mechanic-fragmented)، وهو إستراتيجية تكوين

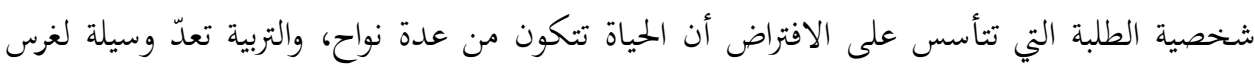

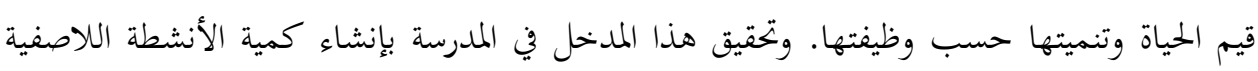
ونوعيتها التي تتركز إلى القيم والخلق.

رابعا: المدخل العضوي النظامي (organic-systemic)، وهو التربية الخلقية هي وحدة متماسكة

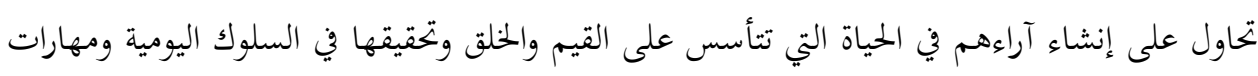
الحياة الخلقية لجميع أعضاء المدرسة.

$$
\text { (V }
$$

أسمى المشكلات في صعوبة تنفيذ التقييم الشامل هي قلة حصة تعليم التربية الإسلامية في

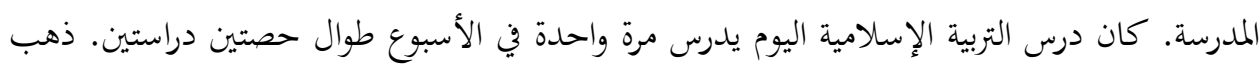
إلى ذلك أحد مدرسي التربية الإسلامية في المدرسة الإعدادية الحكومية با تولونج أغونج. يلزم للحكومة أن تستجيب هذا الواقع بزيادة الحصة الدراسية لمواد التربية الإسلامية في المدرسة.

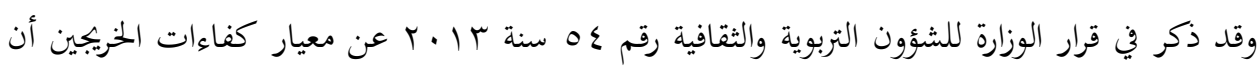
التقييم التربوي يتركز إلى ثلاث نواح، وهي الناحية المعرفية والناحية السلوكية والناحية المهارية. 
كان التقييم الشامل في الحقيقة صعبا للتنفيذ في المدرسة، ذلك لما كان معيار أقل التحصيل

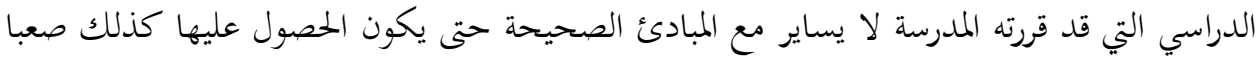

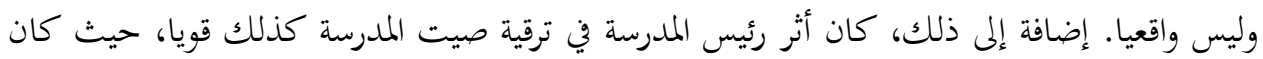
الحصول على سمو معيار أقل التحصيل الدراسي يؤثر في صعوبة تنفيذ التقييم الشامل لمدرسي التربية

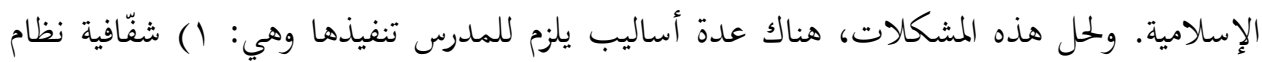
التقييم في بداية الدراسة؛ صناعة الملاحظة اليومية؛ ؟) صناعة الرموز الخاصة؛ ؟) تنمية تعليم الرفاق كالمقيّم؛ 0) صناعة الملاحظة "anekdot“؛ و و) تغيير براديجماتية المدرسين والوالدين.

التقييم الشامل نظريا يساعد على تكوين شخصية الطلبة الكاملة لأنه يتأسس على على عملية

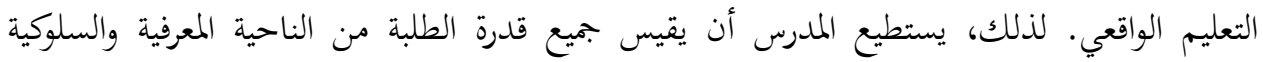

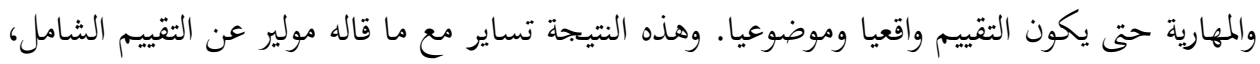

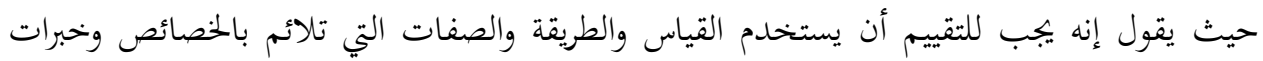
دراسة الطلبة. - ماس.

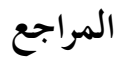

Elaine B. Johson, 2002. Contextual Teaching and Learning; What is and why it's here to stay. California: Corwin Press.

Hart, D., 1994. Authentic Assessment: A Handbook for Educator. California: Addison-Wesley.

Hartati Muchtar, 2010. Penerapan Penilaian Autentik dalam Upaya Peningkatan Mutu Pendidikan. Jurnal Pendidikan Pena bur: Jakarta.

Hibbard, M. 1995. Performance Assessment in the Science Classroom. New York:The McGraw-Hill Companies.

Kuhn, Thomas S. 1996. The Structure of Scientific Revolutions, 3rd edition. Chicago: University of Chicago Press.

M. Ahmad, 1998. Pengembangan Kurikulum, Bandung: Pustaka Setia.

Malik Fadjar, 1998. Visi Pembaharuan Pendidikan Islam. Alfa Grafitakama: Jakarta.

Marjono, 1995. Tes Hasil Belajar. Jakarta: Bumi Aksara.

Mueller, 2006. Authentic Assessment. Nort Central College.

Muhaimin, 2005. Pengembangan Kurikulum Pendidikan Agama Islam. Rajawali Press: Jakarta.

--, cet ke 2, 2002. Paradigma Pendidikan Islam. Remaja Rosda Karya: Bandung.

Nahiyah J Faraz, 2012. Penilain Hasil Belajar. Fak Ekonomi UNY: Jogjakarta. 
O’Malley and Pierce, 1996. Authentic Assessment for English Language Learners;

Practical Approaches for teachers. New York: Addison-Wesley. H. 268

Smith, P. L. 1993. Instructional Design. New York: Mac milllan

Stingins, 1994. Student-Centered Classroom Assessment Upper Saddle River. Merril Prantice Hall.

TR. Moon, et al. 2005. Development of Authentic Assessments for The Middle School Classroom, The Journal of Secondary Gifted Education Vol XVI No. 2/3 Winter Spring.

Wibowo, 2006. Manajemen Perubahan, Jakarta: PT Raja Grafindo Persada.

William Bridges, 2003. Managing Transitions: Making the Most of Change, (Cambridge: Perseus Publishing Services.

Winardi, 2005. Manajemen Perubahan, Jakarta: Kencana.

Winggin, G.P. 1993. Assessing Student Performance: Exploring the Purpose and Limits of Testing. San Fransisco: Jossey Bass.

Worthen dan Sanders, 1973. Educational Evaluation: Theory and Practice. Wadsworth Publishing Compan, Inc. Belmont, California. Zainul dan Nasution, 2001. Penilaian Hasil Belajar. Jakarta: Dirjen Dikti. 


\section{TRANSLITERATION GUIDLINES}

Arabic-Latin transliteration was used in the Jurnal Pendidikan Islam based on the Library of Congress model;

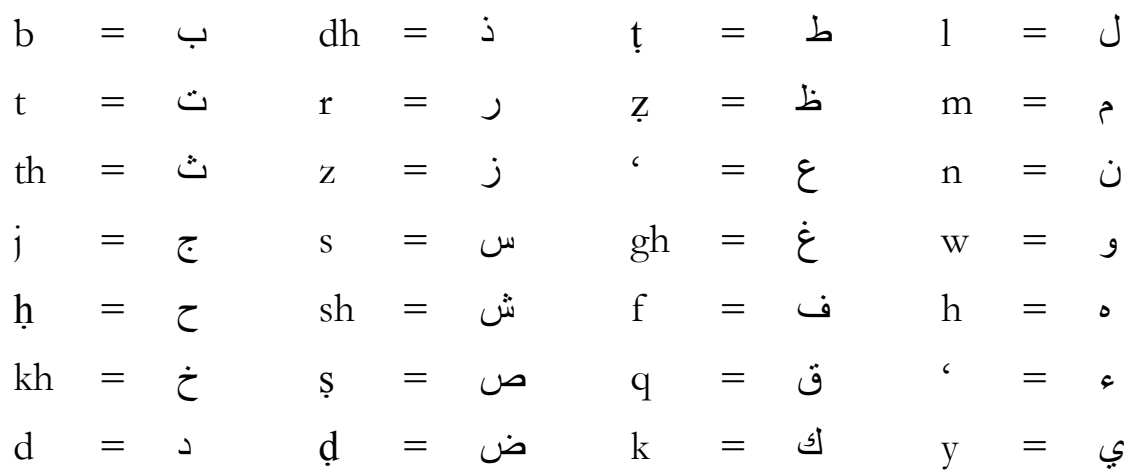

Short vowel $\mathrm{a}=-\quad ; \quad \mathrm{i}=-\quad \mathrm{u}=$ ?

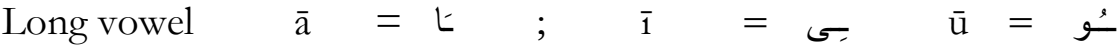

Diphthong ay = ; aw

Note:

1. A word that ends with a ta marbuthah ( $\_$) is transliterated with or without " $h$ "; if the word is the first part of a construct phrase, the ta marbuthah is transliterated into " $\mathrm{t}$ ".

2. An article alif-läm (ال) is transliterated into al-; if it takes place after a preposition, the article alif-lam is transliterated into $l$ -

3. A Qur'anic verse is transliterated according to its pronunciation.

Example:

a. Arabic word in general:

$$
\begin{aligned}
& \text { أهلية } \\
& \text { = Abliyyah atau abliyya } \\
& \text { سورة البقرة - مات } \\
& \text { = Sürat al-Baqarah } \\
& \text { أهل السنة والجماعة } \\
& =\text { Abl as-sunnab wa'l-jamā'ah }
\end{aligned}
$$

b. Qur'anic verses:

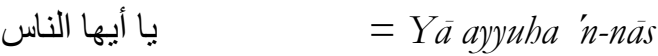

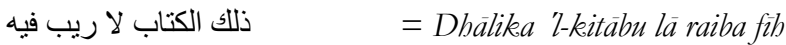

